Supplement of Atmos. Chem. Phys., 15, 13161-13176, 2015

http://www.atmos-chem-phys.net/15/13161/2015/

doi:10.5194/acp-15-13161-2015-supplement

(C) Author(s) 2015. CC Attribution 3.0 License.

(c) (i)

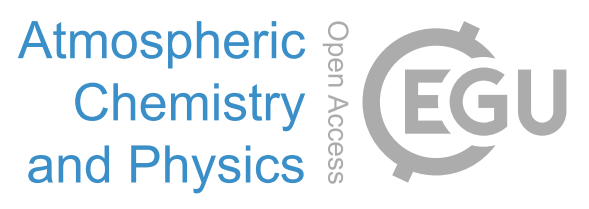

Supplement of

\title{
Reassessment of MIPAS age of air trends and variability
}

\section{F. J. Haenel et al.}

Correspondence to: F. J. Haenel (florian.haenel@ kit.edu)

The copyright of individual parts of the supplement might differ from the CC-BY 3.0 licence. 


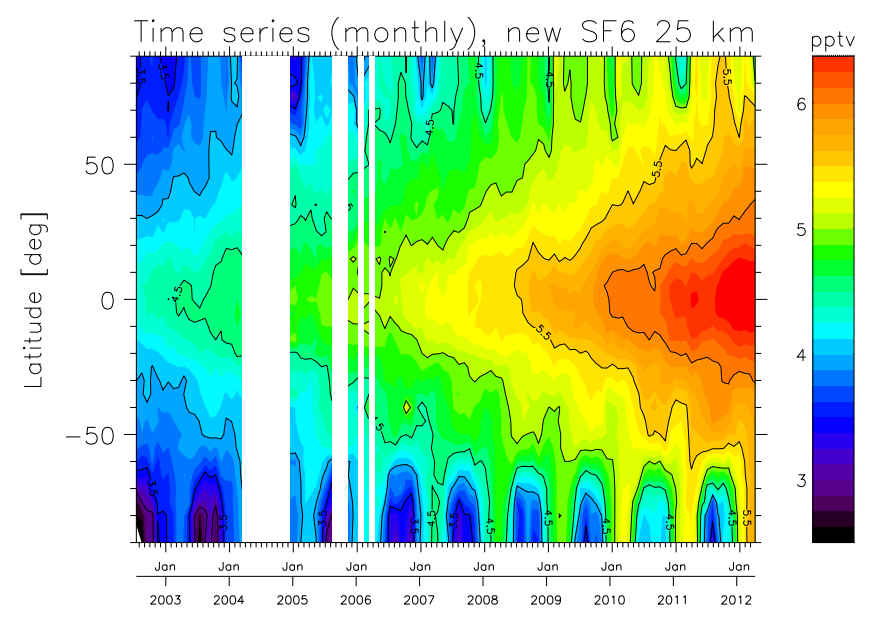

Figure S 1. Timeseries of $\mathrm{SF}_{6}$ monthly zonal means at $25 \mathrm{~km}$.

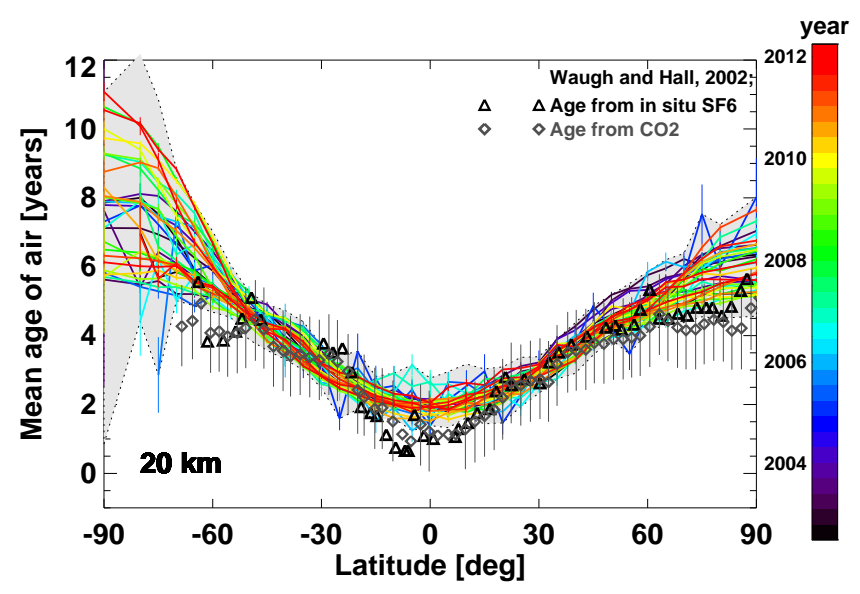

Figure S 2. Comparison of MIPAS AoA latitude cross-sections at $20 \mathrm{~km}$ altitude (coloured curves and shaded area) with AoA derived from earlier airborne $\mathrm{SF}_{6}$ (black triangles) and $\mathrm{CO}_{2}$ measurements (grey diamonds with error bars) as published in Waugh and Hall (2002) and Hall et al. (1999). The shaded area represents the range of all MIPAS monthly mean AoA observations, while the coloured curves show AoA latitudinal dependence for every third month. The colour code provides the time of measurement.

\section{References}

Engel, A., Möbius, T., Bönisch, H., Schmidt, U., Heinz, R., Levin, I., Atlas, E., Aoki, S., Nakazawa, T., Sugawara, S., Moore, F., Hurst, D., Elkins, J., Schauffler, S., Andrews, A., and Boering, K.: Age of stratospheric air unchanged within uncertainties over the past 30 years, Nature Geosci., 2, 28-31, doi 10.1038/ngeo388 2009.

Hall, T. M., Waugh, D. W., Boering, K. A., and Plumb, R. A.: Evaluation of transport in stratospheric models, J. Geophys. Res., 104, 18815-18839, 1999.

Waugh, D. W. and Hall, T. M.: Age of stratospheric air: theory, observations, and models, Rev. Geophys., 40, 1010, doi 10.1029/2000RG000101, 2002.

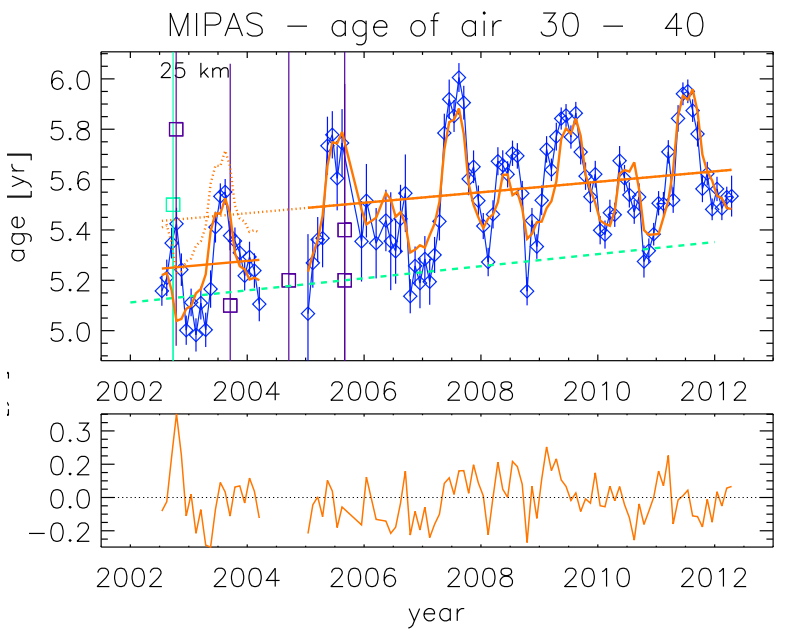

Figure S 3. Example of the fit (in orange) of the regression model to MIPAS AoA monthly means (in blue) at $25 \mathrm{~km}$ for 30 to $40^{\circ} \mathrm{N}$ with consideration of autocorrelation and model errors. The error bars represent the standard error of the mean (SEM). The orange line is the derived trend, squares represent the measurements by Engel et al. (2009) and green dashed line their estimated trend. Underneath the residual of the fit is shown. 

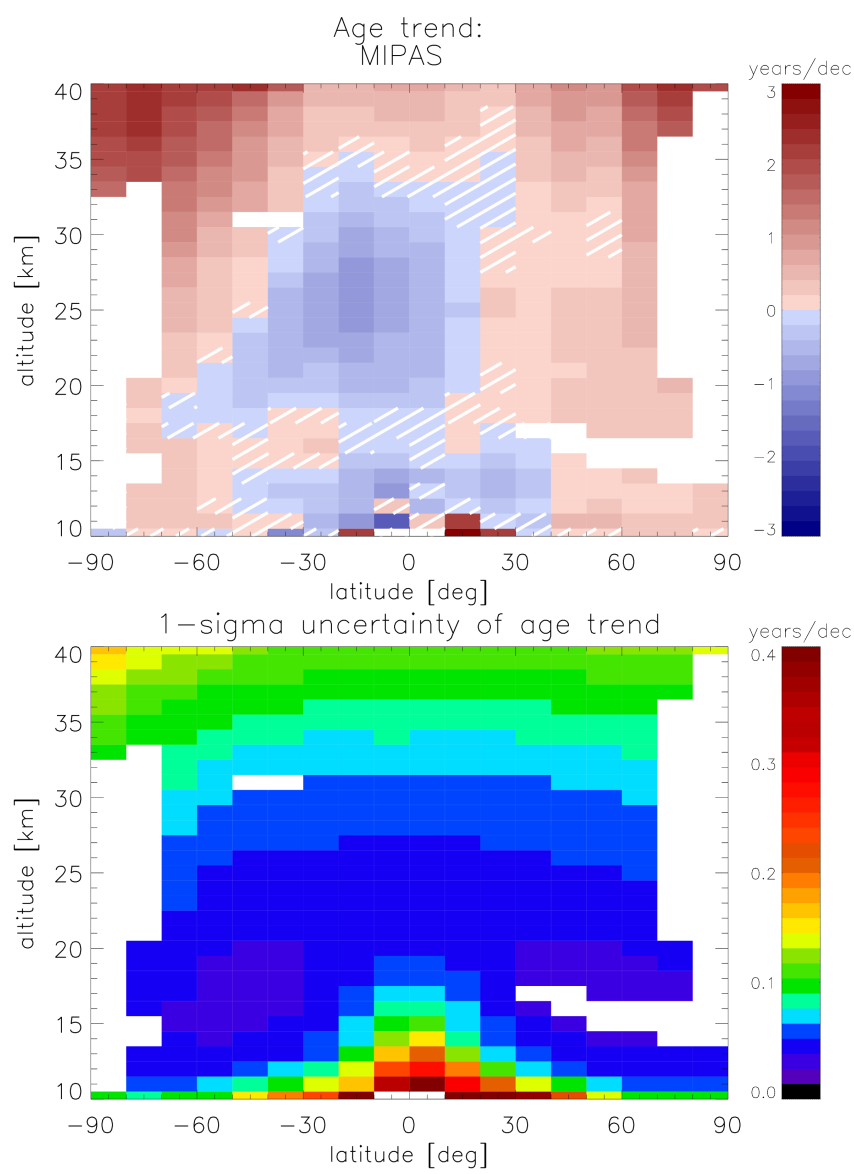

Figure S 4. Altitude-latitude cross-sections of the MIPAS age of air linear increase/decrease over the years 2002 to 2012 without consideration of autocorrelation and model errors (top), together with its $1 \sigma$ uncertainties (bottom). White areas indicate where residuals between measurements and regression model get too large $\left(\chi^{2}>30\right)$. Hatched areas indicate where the trend is not significant.

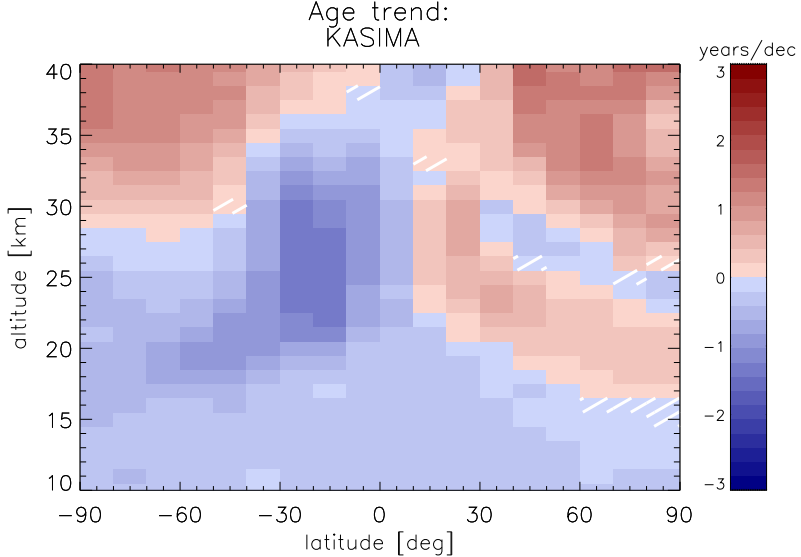

Figure S 5. Altitude-latitude cross-sections of the KASIMA age of air linear increase/decrease over the years 2002 to 2012 without consideration of autocorrelation and model errors. Hatched areas indicate where the trend is not significant. 